\title{
Optimization of Design Parameters of a Stirling Generator for use with a Fluidized Bed Combustor*
}

\author{
S. Lombardi ${ }^{1}$, K. Bizon ${ }^{1}$, F. S. Marra ${ }^{2 * *}$, G. Continillo $^{1}$ \\ ${ }^{1}$ Università degli Studi del Sannio, Facoltà di Ingegneria, Piazza Roma, 82100 Benevento, Italy \\ e-mail: katarzyna.bizon@unisannio.it \\ ${ }^{2}$ Istituto di Ricerche sulla Combustione - CNR, Via Diocleziano 328, 80124, Napoli, Italy \\ e-mail: marra@irc.cnr.it
}

\begin{abstract}
This work investigates the ideal performances that could be achieved in the coupling of a Fluidized Bed Combustor with a Stirling engine by placing the head of a Stirling engine, more specifically the elements of the hot side heat exchanger, in direct contact with the sand of the Fluidized Bed Combustor. This choice is primarily suggested by the heat exchange coefficients between the multiphase fluidized bed medium and the surface of the heat exchanger, much larger than those attained when the heat exchanger is located in the stream of hot flue gases. Moreover, the mechanical action exerted by the fluidized solid particles substantially reduces the fouling usually caused by impurities in exhaust gases of a biomass combustion process.

A mathematical model, which covers a small size fluidized bed and the Stirling engine, is developed and used to optimize design and operating conditions with specific attention to the Stirling hot side heat exchanger. It is shown that the choice to place the heat exchanger in direct contact with the fluidized bed can lead to an improvement of performance in terms of efficiency and shaft power output, making the development of this kind of system attractive for the production of energy from renewable sources.
\end{abstract}

Keywords: Stirling engine; fluidized bed; heat exchanger; renewable energy; optimization.

\section{Introduction}

The idea of using heat generated by combustion as a source for a Stirling Engine (SE) dates back to its invention. The original idea is to place the hot head of the engine as close as possible to the flame, identified with the region of highest temperature and thus ensuring maximum heat transfer between the hot combustion gases and the working fluid of the engine.

The problems that arise with the use of biomass combustion as the heat source for a Stirling Engine are connected with the transfer of heat from the combustion gases to the working fluid. Obviously, the hot side temperature should be as high as possible to achieve acceptable values of specific power and efficiency. The heat exchanger must be designed so that the problems of fouling are minimized (Vos, 2006). When looking at these requirements, the use of fluidized bed (FB) combustion offers, at least in principle, several advantages, listed below.

Typical combustion temperatures in a fluidized bed are of about $850{ }^{\circ} \mathrm{C}$, perfectly compatible with those required for optimal operation of the SE. For example, the typical temperatures required for the supply of SE EG-1000 employed by Sunpower (Kim, et al., 2005) range from 600 ${ }^{\circ} \mathrm{C}(873 \mathrm{~K})$ to $950{ }^{\circ} \mathrm{C}$, with the upper temperature limited by the characteristics of the construction materials.

At these temperatures, emissions of nitrogen oxides are low, to the benefit of the related environmental issues (Lekner, 1998).

Heat transfer rates between the fluidized bed and the surfaces of the heat exchangers immersed in it are typically at least 10 times larger than those between a gas and the heat exchanger (Chen, 2003). This reduces the required surface areas, minimizes the footprint of the equipment, and achieves a high flux at lower temperatures, reducing heat losses in the fumes.

The fluidized bed exerts a physical cleaning action on the surfaces of the heat exchanger, thus maintaining the exchange coefficients stable over time and reducing the need for maintenance (Miccio, 2013).

Because of the high temperatures in the combustion chamber and the risk of fouling, it is not possible to use a Stirling engine designed for natural gas, since the narrow passages in the heat exchanger would soon be blocked when operating with fuels derived from biomass (Theis et al., 2006a). The risk of fouling in processes of combustion of the biomass is primarily due to the formation of aerosols and condensation of the vapours of ash that occur during the cooling of the fumes (Wiinikka et al., 2006; Theis et al., 2006b).

Some solutions coupling a Fluidized Bed Combustor with a Stirling Engine have been already introduced in the recent past (Dong et al., 2009; Miccio 2013) showing the feasibility of this concept. However, neither the FBC nor the Stirling engine components have been specifically designed for this coupling, leaving large uncertainty on the performance at least ideally achievable with this type of systems. Recent developments of this concept are reported in Angrisani et al. (2013).

In this paper, a model that couples the FB combustor

${ }^{*}$ This paper is an updated version of a paper published in the CPOTE 12 proceedings. It is printed here with permission of the authors and organizers. 
with a Stirling engine is developed with this purpose. The model is then adopted to assess the profitability of this layout and the optimal design of the heater when immersed in the FB.

\section{Modeling}

\subsection{Fluidized Bed Combustor}

The model of the FBC has been described in detail in Angrisani et al. (2012). This work addresses the aspects of the model relevant to the coupling with the Stirling Engine model. The description starts from the definition of the control volume, hereinafter $\mathrm{CV}$, identified by the surface that surrounds the volume of the fluidized bed, and interacts with the external environment in different ways, as shown schematically in Fig. 1. It is treated as a Continuous Stirred Tank Reactor (CSTR). The main energy fluxes are, per unit time: the inlet energy carried by the fluidization air, $\dot{Q}_{C, \text { in }}$; the energy delivered to the SE, $\dot{Q}_{S E}$; the outlet energy carried by the hot gases leaving the $\mathrm{FB}$, sum of fluidization air and combustion gases, $\dot{Q}_{C, \text { out }}$; the heat transferred by radiation from the FB surface, $\dot{Q}_{R, \text { out }}$. The energy balance has to take into account also the thermal power due to biomass combustion, $\left(\dot{m}_{f u e l} L H V_{\text {fuel }}\right)$, and the mechanical power required for fluidization, $P_{f l}$. Under typical conditions of operation of a FB, the temperature rapidly homogenises between the solid and the gas phase, so that a single temperature can be used for the entire emulsion, $T_{\text {bed }}$. Furthermore, the gas velocity is everywhere low, in the order of few meters per second or less. Also, the overpressure needed to fluidize the bed is relatively small. It is thus reasonable to neglect pressure variations in the bed and to assume that density variations are due primarily to changes in temperature (subsonic motion), resulting in $\rho_{g} T_{b e d}=$ constant .

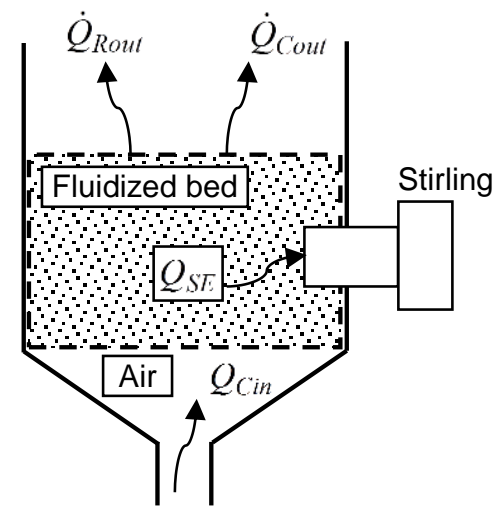

Figure 1. Control volume of the FBC and thermal fluxes.

The total energy variation in the control volume $(\mathrm{CV})$ is approximated as:

$$
\begin{aligned}
\frac{d}{d t} E & =\frac{d}{d t}\left(\rho_{g} T_{g} c_{p g} V_{g}\right)_{g}+\frac{d}{d t}\left(\rho_{s} c_{p s} V_{s} T_{s}\right)_{s} \\
& \approx \rho_{s} V_{s} c_{p s} \frac{d T_{b e d}}{d t}=m_{s} c_{p s} \frac{d T_{b e d}}{d t}
\end{aligned}
$$

Subscripts $g$ and $s$ are used to refer to gas and solid phase respectively, in refers to inlet conditions.
The total energy balance in the FB assumes the form given by the following expression:

$$
\begin{aligned}
& \frac{d T_{\text {bed }}}{d t}=\frac{1}{m_{s} c_{p s}} {\left[\dot{Q}_{C, \text { in }}-\dot{Q}_{C, \text { out }}-\dot{Q}_{S E}\right.} \\
&\left.-\dot{Q}_{R, \text { out }}+\dot{m}_{f u e l} L H V_{f u e l}-P_{f l}\right]
\end{aligned}
$$

where $\dot{Q}_{S E}$ is thermal flux absorbed by the heater of the Stirling engine, and it is given by:

$\dot{Q}_{S E}=U_{b} A_{e x t, h}\left(T_{b e d}-T_{h}\right)$

$U_{b}$ is the heat transfer coefficient between the fluidized bed and the heater of the Stirling engine, $A_{\text {ext }, h}$ is the thermal exchange area of the heater, and $T_{h}$ is the wall temperature of the heater. The heat transfer coefficient $U_{b}$ is about 200 $\mathrm{W} /\left(\mathrm{m}^{2} \mathrm{~K}\right)$.

\subsection{Stirling Engine: Bandurich-Normani Model}

The Stirling engine is modelled following (Normani, 2009) who in turn followed (Bandurich \& Chen, 1984). The engine is considered partitioned in the following control volumes (Figure 2): the compression space $V_{c}$; the expansion space $V_{e}$; the heater volume $V_{h}$; the cooler volume $V_{k}$; and the regenerator volume $V_{r}$. Cooler, heater and regenerator volumes constitute the dead volume $V_{d}$.

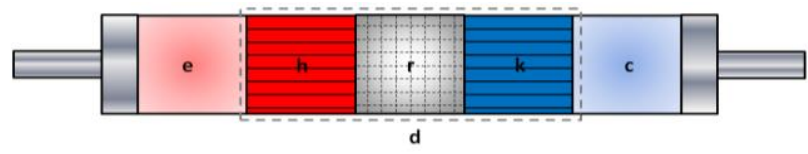

Figure 2. Control volumes of the Stirling engine model.

The mathematical model is derived by writing the conservation of mass and energy for each control volume, obtaining a system of differential-algebraic equations (DAEs). The following assumptions are made:

- the system is closed (there is no fluid leakage);

- the working fluid is considered ideal;

- effects of inertia of the working fluid are negligible;

- the dead space is isothermal;

- pressure in the dead space is uniform;

- compression and expansion spaces are adiabatic;

- the volumes of the compression and expansion spaces vary in time with sinusoidal law;

- wall temperatures of heater and cooler are uniform and constant;

- gas temperatures in the heater and in the cooler are constant and equal to the temperature of heater and of the cooler, respectively;

- $80 \%$ of total pressure drop occurs inside the regenerator (Chen \& Griffin, 1983).

\section{Compression and expansion spaces $\left(V_{c}\right.$ and $\left.V_{e}\right)$}

Conservation of mass in the compression space (Figure 2) is expressed as:

$$
\frac{d m_{c}}{d t}=\dot{m}_{c k}
$$


where $m_{c}$ is the mass of the working fluid present inside the compression space and $\dot{m}_{c k}$ the mass flow directed from the cooler to the compression space (positive if incoming). Applying the first law of thermodynamics to the compression space, we obtain the following equation:

$$
\frac{d\left(m_{c} c_{v} T_{c}\right)}{d t}=-p_{c} \frac{d V_{c}}{d t}+\frac{d m_{c}}{d t} c_{p} T_{c k}
$$

where $T_{c k}$ is an interfacial temperature:

$T_{c k}= \begin{cases}T_{k} & \text { if } \frac{d m_{c}}{d t}>0 \\ T_{c} & \text { if } \frac{d m_{c}}{d t}<0\end{cases}$

By substitution of the equation of state of ideal gases into Eq. (5):

$$
\frac{d p_{c}}{d t}=-\gamma \frac{p_{c}}{V_{c}} \frac{d V_{c}}{d t}+\frac{d m_{c}}{d t} \frac{R \gamma T_{c k}}{V_{c}}
$$

Similarly, it is possible to extend the previous formulation to the expansion space (Figure 2), obtaining:

$$
\begin{aligned}
\frac{d m_{e}}{d t} & =\dot{m}_{e h} \\
\frac{d p_{e}}{d t} & =-\gamma \frac{p_{e}}{V_{e}} \frac{d V_{e}}{d t}+\frac{d m_{e}}{d t} \frac{R \gamma T_{e h}}{V_{e}}
\end{aligned}
$$

where: $m_{e}$ is the mass of the working fluid present inside the expansion space; $\dot{m}_{e h}$ is the mass flow rate from the heater to the expansion space; $T_{e h}$ is the interfacial (or conditional) temperature:

$T_{e h}= \begin{cases}T_{h} & \text { if } \frac{d m_{e}}{d t}>0 \\ T_{e} & \text { if } \frac{d m_{e}}{d t}<0\end{cases}$

In Eqs. (7) and (9) the terms concerning expansion and compression volumes and their time derivatives are assigned functions given by:

$$
\begin{aligned}
& V_{e}=V_{\text {min }, e}+0.5 V_{\text {swept }, e}+0.5 V_{\text {swept }, e} \sin (2 \pi f \cdot t+\beta) \\
& V_{c}=V_{\text {min }, c}+0.5 V_{\text {swept }, c}+0.5 V_{\text {swept }, c} \sin (2 \pi f \cdot t) \\
& \frac{d V_{e}}{d t}=0.5 V_{\text {swept }, e} 2 \pi f \cdot t \cos (2 \pi f \cdot t+\beta) \\
& \frac{d V_{c}}{d t}=0.5 V_{\text {swept }, c} 2 \pi f \sin (2 \pi f \cdot t)
\end{aligned}
$$

\section{Dead space $\left(V_{d}\right)$}

The total mass of the working fluid is given by:

$$
m_{t o t}=m_{e}+m_{c}+m_{d}=\text { constant }
$$

where $m_{d}$ is the instantaneous value of the mass of fluid in the dead space. It is:

$$
\frac{d m_{e}}{d t}+\frac{d m_{c}}{d t}+\frac{d m_{d}}{d t}=0
$$

By differentiating the equation of state of ideal gases for the dead space, $p_{d} V_{d}=m_{d} R T_{d}$, we obtain:

$\frac{d m_{d}}{d t}=\frac{V_{d}}{R T_{d}} \frac{d p_{d}}{d t}$

where $V_{d}$ (volume of the dead space) and $T_{d}$ (average temperature of working fluid inside the dead space) are constant. $T_{d}$ is calculated as (Normani, 2009):

$$
T_{d}=\frac{V_{d}}{\frac{V_{h}}{T_{h}}+\frac{V_{k}}{T_{k}}+\frac{V_{r e g}}{T_{r e g}}} .
$$

Here $T_{\text {reg }}$, the effective temperature of the regenerator, is given by

$$
T_{\text {reg }}=\frac{\left(1-\varepsilon_{1}\right) T_{h}-\left(1+\varepsilon_{2}\right) T_{k}}{\ln \left(\frac{\left(1-\varepsilon_{1}\right) T_{h}}{\left(1+\varepsilon_{2}\right) T_{k}}\right)}
$$

where $V_{d}$ is the total volume of the dead space, $V_{d}=V_{h}+V_{k}+V_{r}$. In Eq. 16, $1-\varepsilon_{1}$ and $1+\varepsilon_{2}$ account for the effectiveness of heater and cooler respectively. Substituting equation (13) into equation (14), we obtain:

$\frac{d p_{d}}{d t}=-\frac{R T_{d}}{V_{d}}\left(\frac{d m_{e}}{d t}+\frac{d m_{c}}{d t}\right)=-\frac{R T_{d}}{V_{d}}\left(\dot{m}_{e h}+\dot{m}_{c k}\right)$

The mass flow rates $\dot{m}_{e h}$ and $\dot{m}_{c k}$ depend on the pressure drops (Incropera \& DeWitt, 1996):

$$
\begin{gathered}
\frac{d m_{c}}{d t}=\dot{m}_{c h}=K_{d c}\left(p_{d}-p_{c}\right)^{n} d c \\
\frac{d m_{e}}{d t}=\dot{m}_{e h}=K_{d e}\left(p_{d}-p_{e}\right)^{n_{d e}}
\end{gathered}
$$

where the transport coefficients $K_{d e}, K_{d c}, n_{d e}$ and $n_{d c}$ are constant. The values $n_{d e}$ and $n_{d c}$ are both fixed to $5 / 9=$ $1 / 1.8$ in Normani (2009), whereas Bandurich \& Chen (1984) propose for both the value $1 / 1.75$. In this work, the value $5 / 9$ is chosen. The transport coefficients $K_{d e}$ and $K_{d c}$ depend on various parameters, i.e. engine speed, geometric parameters of the heat exchangers of the heater and cooler (number of tubes, average length of the tubes, average diameter of the tubes), type of the working fluid (air, hydrogen, helium). The calculation procedure of $K_{d e}$ and $K_{d c}$ is reported in Normani, 2009. The whole system of equations governing the Stirling engine is summarized in Table 1

The thermal power absorbed is obviously given by $\dot{Q}_{h}=f \cdot Q_{h}$, where $f$ is the operating frequency of the engine, and $Q_{h}$ is the heat absorbed per cycle, given by the area under the expansion curve in the $p-V$ plane. The shaft power is given by:

$P=f W=f\left[\oint p_{c} d V_{c}+\oint p_{e} d V_{e}\right]$

Finally, the efficiency of the Stirling engine is given by:

$\eta_{S E}=P / \dot{Q}_{h}$ 
Table 1. Model equations of the Stirling engine.

Differential equations

$\frac{d p_{c}}{d t}=-\gamma \frac{p_{c}}{V_{c}} \frac{d V_{c}}{d t}+\frac{d m_{c}}{d t} \frac{R \gamma T_{c k}}{V_{c}}$

$\frac{d p_{e}}{d t}=-\gamma \frac{p_{e}}{V_{e}} \frac{d V_{e}}{d t}+\frac{d m_{e}}{d t} \frac{R \gamma T_{e h}}{V_{e}}$

$\frac{d p_{d}}{d t}=-\frac{R T_{d}}{V_{d}}\left(\frac{d m_{e}}{d t}+\frac{d m_{c}}{d t}\right)$

$\frac{d m_{c}}{d t}=K_{d c}\left(p_{d}-p_{c}\right)^{n_{d c}}$

$\frac{d m_{e}}{d t}=K_{d e}\left(p_{d}-p_{e}\right)^{n} d e$

Algebraic equations

$$
\begin{aligned}
& T_{d}=\frac{V_{d}}{\frac{V_{h}}{T_{h}}+\frac{V_{k}}{T_{k}}+\frac{V_{r e g}}{T_{r e g}}} \\
& T_{r e g}=\frac{\left(1-\varepsilon_{1}\right) T_{h}-\left(1+\varepsilon_{2}\right) T_{k}}{\ln \left(\frac{\left(1-\varepsilon_{1}\right) T_{h}}{\left(1+\varepsilon_{2}\right) T_{k}}\right)} \\
& V_{d}=V_{h}+V_{k}+V_{r} \\
& T_{c k}=T_{c}+1 / 2\left(1+\frac{d m_{c} / d t}{\left|d m_{c} / d t\right|}\right)\left(T_{k}-T_{c}\right) \\
& T_{e h}=T_{e}+1 / 2\left(1+\frac{d m_{e} / d t}{\left|d m_{e} / d t\right|}\right)\left(T_{h}-T_{e}\right) \\
& p V=m R T
\end{aligned}
$$

\subsection{The Coupled Model}

The coupled model is made of the steady state CSTR model of the fluidized bed combustor and the BandurichNormani model for the Stirling engine. Coupling consists of equating the thermal flux $\dot{Q}_{S E}$ from the fluidized bed to the Stirling engine, and $\dot{Q}_{h}$, the thermal flux absorbed by the Stirling engine as it appears in the Bandurich-Normani model. Therefore, the coupling condition of the model can be written as:

$$
\dot{Q}_{S E}=\dot{Q}_{h} \Leftrightarrow \dot{Q}_{h}=U_{b} A_{e x t, h}\left(T_{b e d}-T_{h}\right)
$$

This coupling condition is justified since, at steady state, the thermal power absorbed by the engine is equal to that transferred from the bed to the heat exchanger of the heater: if this were not true, the wall temperature of the heater would increase and, as a consequence, the assumption of steady state would no longer be true.

The convergence test of the coupled model is conducted on the wall temperature of the heat exchanger of the heater, fixing a maximum error of $10^{-5}$.

On account of the coupled model, it is then possible to define the global efficiency $\eta$ of the system as the ratio between the shaft power Eq. (20) and the chemical energy flux:

$$
\eta=\frac{P}{\dot{m}_{\text {fuel }} L H V_{\text {fuel }}}
$$

\section{Design Optimization}

Generally, all engineering optimization problems in their essence have a multi-objective character and, moreover, very often conflicting objectives have to be fulfilled. The usual approach to the optimization of such problems consists of assigning a priori some level of importance to the objectives and reducing the problem to a single objective to be optimized and a number of secondary objectives formulated in the form of constraints (Di Barba, 2010). The main disadvantage of such approach is that, even though the main objective is brought to its best, in most cases the secondary objectives might still be improved by keeping the main objective constant, which means that an overall better solution exists (Di Barba, 2010). Hence, when more relevant objectives have to be fulfilled, it is more convenient and correct to consider a multi-objective optimization approach. In such approach, objectives are not anymore hierarchized or reduced to constraints, and the optimization problem consists of the search of the compromise optimum. Formally, a multi-objective optimization problem can be defined as (Di Barba, 2010):

given $x_{0} \in \mathbf{R}^{n_{v}}$, find inf $F(x), x \in \mathbf{R}^{n_{v}}$

where $n_{v}$ is the number of the variables and $F(x)=\left\{f_{1}(x), \ldots, f_{n_{f}}(x)\right\} \subset \mathbf{R}^{n_{f}}$ is the objective vector composed of $n_{f} \geq 2$ terms, subject to $n_{c}$ and $n_{e}$ inequality and equality constrains, respectively:

$g_{i}(x) \leq 0, i=1, \ldots, n_{c} ; h_{i}(x)=0, i=1, \ldots, n_{e}$

and $2 n_{v}$ side bonds:

$l_{k} \leq x_{k} \leq u_{k}, k=1, \ldots, n_{v}$

Traditionally, the problem is reformulated by introducing the preference function $\psi(x)$, for example the weighted sum of the objectives:

$\psi(x)=\sum_{i=1}^{n_{f}} c_{i} f_{i}(x)$

with $0<c_{i}<1, \sum_{i=1}^{n_{f}} c_{i}=1$, to be minimized with respect to $x \in \mathbf{R}^{n_{v}}$, hence it is clear that the hierarchy of the objectives - and so the optimal solution - still depends on the attributed weights $c_{i}$.

An alternative approach to the multi-objective problems has been introduced by Pareto (1896). The aim of the Paretian multi-objective optimization is a search of all non-dominated compromise solutions, also called efficient solutions, in the space of the decision variables. It is said that a solution dominates another one if the first is better than the second with respect to one objective, without worsening all the other objective functions. On the other hand, two solution are called indifferent if the first is better than the second for some objectives, while the second is better than the first in all other objectives. Let us define an objective space $Y \subseteq \mathbf{R}^{n} f$. Then a point $y \in Y$ is said to be 'Pareto optimal' (blue points in Fig. 3) if no point $\tilde{y} \in Y$ exists such that $F^{-1}(\tilde{y})$ dominates $F^{-1}(y)$. A set of the solutions $\Phi=\{y \in Y \mid y$ is Pareto optimal $\}$ is called 'Pareto front' (red-dashed line in Fig. 3). $\Xi=\{x \in X \mid F(x) \in \Phi\}$ is called 'Pareto set'. The two sets $\Phi$ and $\Xi$ characterize the solution of the multi-objective problem. 


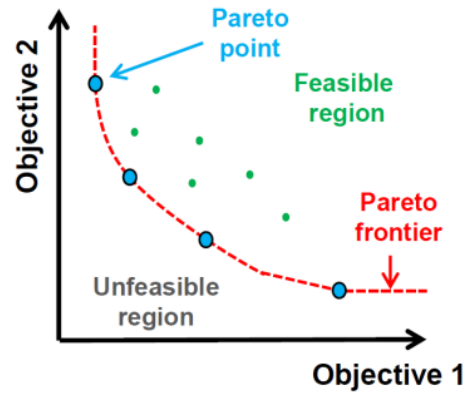

Figure 3. Objective space for the problem with two objectives.

From the computational point of view, the problem of multi-objective optimization can be faced through a number of evolutionary optimization algorithms based on genetic algorithms and neural networks (Eslick \& Miller, 2012) as well as on traditional deterministic methods (Logist, et al., 2009). In order to approach optimization problems of different type and complexity, specific multi-objective software tools have been developed, among which modeFRONTIER being perhaps the most powerful (www.esteco.com). Based on a number of proprietary algorithms available on the platform, it is featured by an open character which permits integration with other commercial (e.g. Matlab, Excel) and non-commercial software.

Specifically, for the system presented earlier, we want to maximize both the global efficiency $\eta$ and the shaft power $P$ yielded by the Stirling engine. Thus, let $\mathbf{x}$ be the vector of the decision variables as:

$$
\mathbf{x}=\left[\dot{m}_{\text {fuel }}, r p m, N_{h}, D_{h}, L_{h}\right]^{T}
$$

where $\dot{m}_{f u e l}$ is the mass flow rate of fuel fed to the system, rpm is the engine speed, $N_{h}, D_{h}$ and $L_{h}$ are respectively the number, diameter and average length of the pipes that constitute the heat exchanger of the heater. The variables $\dot{m}_{\text {fuel }}$ and rpm correspond to operating parameters whereas the variables $N_{h}, D_{h}$ and $L_{h}$ correspond to design parameters. Therefore, the multi-objective problem (MOP) can be written as

$$
\max _{\mathbf{x} \in \mathbf{X}} F(\mathbf{x})
$$

where $\mathbf{F}(\mathbf{x})=[\eta(\mathbf{x}), P(\mathbf{x})]^{T}$ is the objective vector, and $\mathbf{X}$ is the feasible region in the space of the decision variables. The set of lower and upper bounds on the decision variables are reported in Table 2. Fuel consumption bounds are enforced by the design target power of the system. The range for the engine rotation speed corresponds to values observed in real Stirling engines.

Geometrical constraints are suggested by the overall obstruction of the heat exchanger with respect to the size of the bed, and by the need to not reduce too much the section of the tubes of the heat exchanger to avoid an excessive pressure loss for the working fluid in the Stirling engine.

Mechanical constraints limit the temperature of the fluidized to stay lower than $1000^{\circ} \mathrm{C}$. Finally, a constraint of good design is that the dead volume of the Stirling engine must be less than $60 \%$ of the free volume to gas inside of the Stirling engine (Walker, 1980).

Table 2. Set of lower and upper boundaries for the decision variables.

\begin{aligned} & \hline $\mathbf{L B} \leq$ decision variable $\leq \mathbf{U B} \\ &$\hline $4 \mathrm{~kg} / \mathrm{h} \leq \dot{m}_{f u e l} \leq 20 \mathrm{~kg} / \mathrm{h} \\ & 400 \leq \mathrm{rpm} \leq 900 \\ & 4 \leq N_{h} \leq 40 \\ & 5 \mathrm{~mm} \leq D_{h} \leq 8 \mathrm{~mm} \\ & 8 \mathrm{~cm} \leq L_{h} \leq 40 \mathrm{~cm}\end{aligned}$

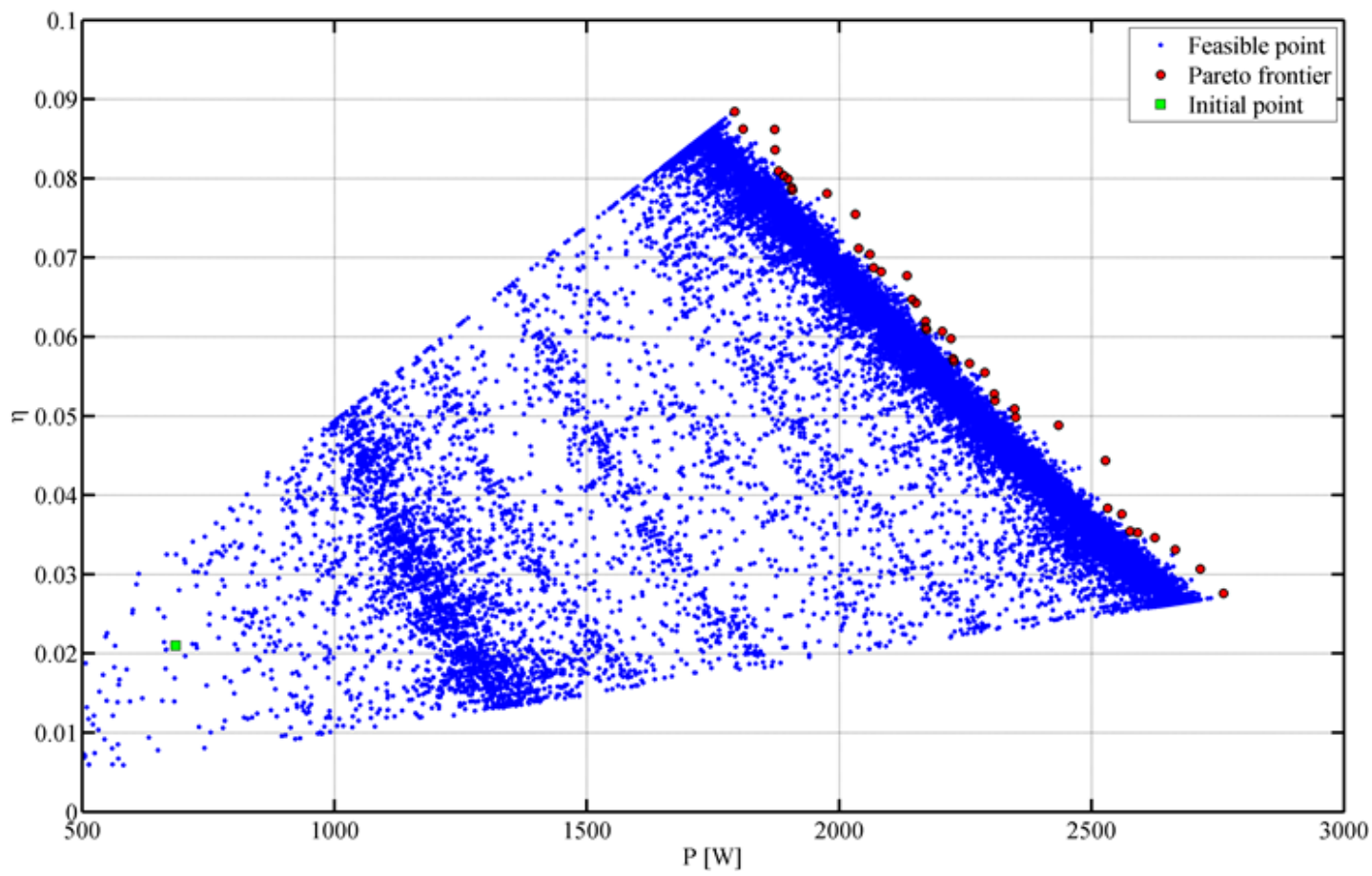

Figure 4 - Feasible points (blue), in the objective space (shaft power, global efficiency) of Stirling Power and global efficiency. Red points represent the Pareto frontier of optimal solutions. 


\section{Results}

The problem formulated in the previous section was solved by using the software modeFRONTIER, in particular the employed multi-objective optimization algorithm was the MOGA II (Multi Objective Genetic Algorithm).

Figure 4 shows the results of the optimization procedure in the objective space. It can be noticed that the performance of the Pareto solutions (Pareto frontier) are much better than those obtained at the initial point. The Pareto solution with the maximum efficiency presents a shaft power of about $1.75 \mathrm{~kW}$ with an efficiency of about 9\%. However, the Pareto solution with maximum shaft power presents values of efficiency and shaft power of about $3 \%$ and $2.7 \mathrm{~kW}$ respectively.

Figures 5 and 6 shows that the Pareto solution with the maximum efficiency occurs at a bed temperatures lower than the temperature at which the Pareto solution returns the maximum shaft power. Indeed, the increase of the temperature causes an increase of the efficiency of the Stirling engine, as it is well known from the literature, and an increase of the shaft power, as shown in Figure 6, but also an increase of the convective losses of heat with the exiting exhaust gases. In terms of global efficiency, convective heat losses overrule the increase of efficiency of the Stirling engine.

Figures 7 and 8 report global efficiency and shaft power versus fuel mass flow rate. These plots show that the maximum of the global efficiency occurs at the lower bound of the mass flow rate, whereas the maximum of the shaft power yielded by the Stirling engine occurs at the upper bound of the mass flow rate. It is interesting to note that a significant increase of the shaft power occurs only up to a fuel mass flow rate of about $10 \mathrm{~kg} / \mathrm{h}$. This value represents, therefore, a practical limit of the nominal power of the system. Table 3 reports the values of the optimization parameters at three points of the Pareto frontier, together with some indicative quantities. It clearly emerges that, to sustain the output of shaft power, a high value of the heat transferred to the engine has to be ensured. This is obtained by changing the geometry of the heater, recovering a higher heat flux by increasing the exchange surface area. However this leads to a decrease of the Stirling efficiency while the set of optimal parameter values is adjusted to keep the global efficiency as high as possible, therefore minimizing fuel consumption.

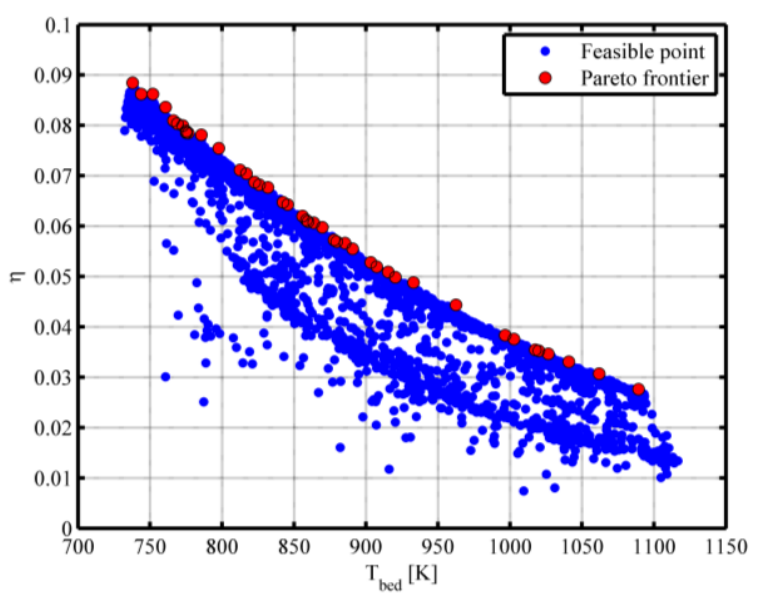

Figure 5. Global efficiency versus $T_{b}$.

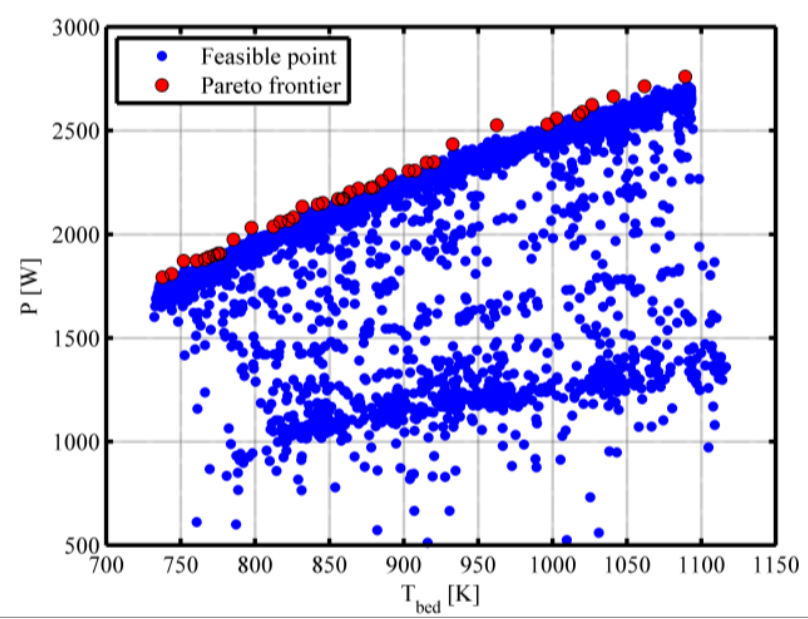

Figure 6. Shaft power versus $T_{\text {bed }}$.

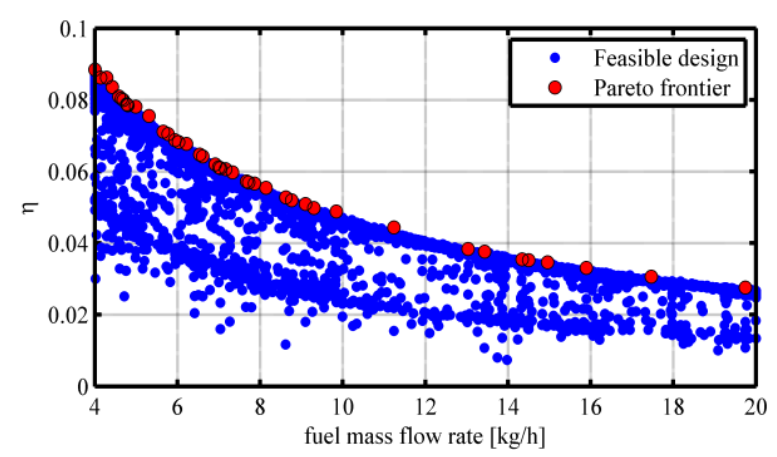

Figure 7. Global efficiency versus fuel mass flow rate.

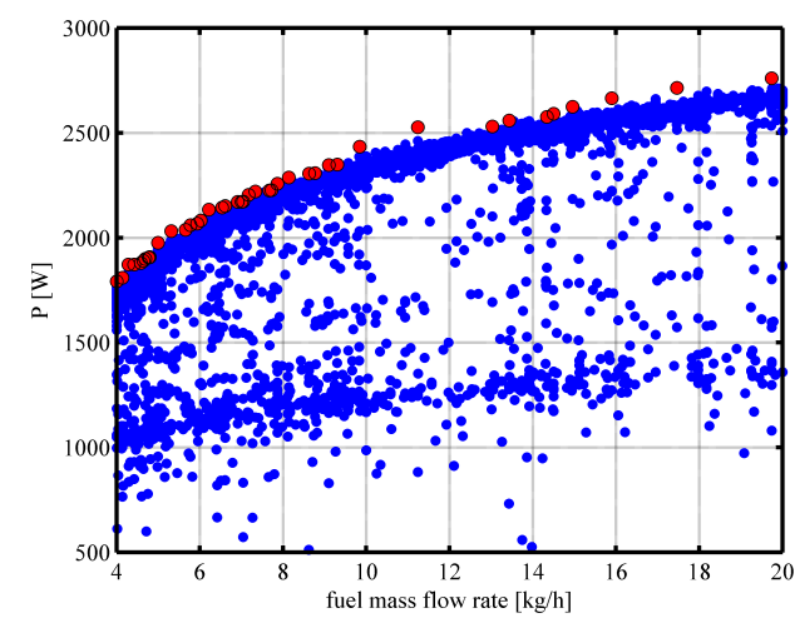

Figure 8. Shaft power versus fuel mass flow rate. 
Table 3. Value of optimization parameters at three points on the Pareto frontier and corresponding values of some model variables.

\begin{tabular}{cccc}
\hline$\dot{m}_{\text {fuel }}[\mathrm{kg} / \mathrm{h}]$ & 19.74 & 9.84 & 4.00 \\
$\mathrm{rpm}$ & 899.80 & 899.90 & 899.00 \\
$D_{h}[\mathrm{~mm}]$ & 5.59 & 6.10 & 5.77 \\
$L_{h}[\mathrm{~cm}]$ & 8.031 & 8.032 & 8.035 \\
$N_{h}$ & 23 & 21 & 34 \\
\hline$V_{h}\left[\mathrm{~cm}^{3}\right]$ & 45.36 & 49.30 & 71.34 \\
$A_{\text {ext }, h}\left[\mathrm{~cm}^{2}\right]$ & 324.51 & 323.27 & 494.87 \\
$\dot{Q}_{S E}[\mathrm{~kW}]$ & 10.96 & 10.88 & 10.88 \\
$T_{h}[\mathrm{~K}]$ & 1030 & 869 & 698 \\
$T_{b e d}[\mathrm{~K}]$ & 1089 & 933 & 738 \\
$\eta_{S E}$ & 0.25 & 0.22 & 0.16 \\
\hline$\eta$ & 0.03 & 0.05 & 0.09 \\
$P[\mathrm{~kW}]$ & 2.76 & 2.43 & 1.79 \\
\hline
\end{tabular}

5. Conclusions

An integrated model for a novel FBC-Stirling engine cogeneration system has been developed and coupled with the optimization software modeFRONTIER. The solutions on the Pareto frontier are all optimal in the Pareto sense, i.e. they are compromise solutions satisfying the objectives as best possible, and the choice of a particular solution is left to the user and/or the designer.

From the results of the optimization procedure, aiming at maximizing both the mechanical power produced by the Stirling and the global efficiency, it clearly emerges that, by increasing fuel consumption, the bed temperature increases - but so do heat losses from the system, leading to an overall decrease of the effective power.

The results indicate that the maximum efficiency of the system does not occur at the highest efficiency of the Stirling engine. This can be explained by the fact that the power carried by the exhaust gases is very high. Therefore, this consideration suggests that the system can best be employed for cogenerative uses.

\section{Acknowledgements:}

This project is partly supported by the Italian Ministry for the environment, territory and sea protection (MATTM) under contract named MEGARIS.

\section{Nomenclature}

$A_{\text {ext }, h} \quad$ exchange area of the SE heater, $\mathrm{m}^{2}$

$c_{p g} \quad$ specific heat of the gas phase, $\mathrm{kJ} /(\mathrm{kg} \mathrm{K})$

$c_{p s} \quad$ specific heat of the gas phase, $\mathrm{kJ} /(\mathrm{kg} \mathrm{K})$

$c_{p} \quad$ constant pressure specific heat of the working fluid, $\mathrm{kJ} /(\mathrm{kg} \mathrm{K})$

$c_{v} \quad$ constant volume specific heat of the working fluid, $\mathrm{kJ} /(\mathrm{kg} \mathrm{K})$

$D_{h} \quad$ pipe diameter of the heater, $\mathrm{mm}$

$f \quad$ SE frequency, $\mathrm{Hz}$

$K_{d c}, n_{d c}$ transport coefficients between dead and compression spaces.
$K_{d c}, n_{d c}$ transport coefficients between dead and expansion spaces.

$L_{h} \quad$ pipe average length of the heater, $\mathrm{cm}$

$L H V_{\text {fuel }}$ Lower Heating Value of the fuel, $\mathrm{kJ} / \mathrm{kg}$

$\dot{m}_{\text {air }} \quad$ mass flux of air, $\mathrm{kg} / \mathrm{s}$

$\dot{m}_{\text {fuel }} \quad$ mass flux of fuel, $\mathrm{kg} / \mathrm{s}$

$m_{c} \quad$ mass of the working fluid in the compression space, $\mathrm{kg}$

$m_{d} \quad$ mass of the working fluid present in the dead space, $\mathrm{kg}$

$m_{e} \quad$ mass of the working fluid present in the expansion space, $\mathrm{kg}$

total mass of the working fluid, $\mathrm{kg}$

$m_{\text {tot }}$

$\dot{m}_{\text {fuel }}$

$\dot{m}_{c k}$

$\dot{m}_{e h}$

$N_{h}$

$P$

$P_{f l}$ mass flux of fuel, $\mathrm{kg} / \mathrm{s}$

mass flow rate from the cooler to the compression space, $\mathrm{kg} / \mathrm{s}$

mass flow rate from the heater to the expansion space, $\mathrm{kg} / \mathrm{s}$

number of pipes in the heater useful mechanical power produced by the SE, W mechanical power required for fluidization, $\mathrm{W}$

$p_{c} \quad$ pressure in the compression space, $\mathrm{K}$

$p_{d} \quad$ pressure in the dead space, $\mathrm{K}$

$p_{e} \quad$ pressure in the expansion space, $\mathrm{K}$

$\dot{Q}_{C, \text { in }} \quad$ heat flux entering the system with the feed air, W

$\dot{Q}_{C, \text { out }} \quad$ heat losses by convection, W

$\dot{Q}_{h} \quad$ heat flux absorbed by the SE as it appears in the Bandurich-Normani model, W

$\dot{Q}_{R, \text { out }}$ heat losses by radiation from the FB surface, W

$\dot{Q}_{S E} \quad$ heat flux transferred to the Stirling Engine, W

$t \quad$ time, $\mathrm{s}$

$T_{\text {bed }} \quad$ temperature in the fluidized bed, $\mathrm{K}$

$T_{c} \quad$ temperature in the compression space, $\mathrm{K}$

$T_{d} \quad$ average temperature in the dead space, $\mathrm{K}$

$T_{e} \quad$ temperature in the expansion space, $\mathrm{K}$

$T_{h} \quad$ temperature of the heater, $\mathrm{K}$

$T_{k} \quad$ temperature of the cooler, $\mathrm{K}$

$T_{c k}$ temperature at the interface between the compression space and the cooler, $\mathrm{K}$

$T_{e h} \quad$ temperature at the interface between the expansion space and the heater, $\mathrm{K}$

$T_{\text {reg }} \quad$ effective temperature of the regenerator, $\mathrm{K}$

$U_{b} \quad$ heat transfer coefficient between the fluidized bed and the SE heater, $\mathrm{W} /\left(\mathrm{m}^{2} \mathrm{~K}\right)$

$V_{c} \quad$ volume of the compression space, $\mathrm{K}$

$V_{d} \quad$ volume of the dead space, $\mathrm{K}$

$V_{e} \quad$ volume of the expansion space, $\mathrm{K}$

$V_{h} \quad$ volume of the heater, K

$V_{k} \quad$ volume of the cooler, $\mathrm{K}$

$V_{\text {reg }} \quad$ void volume inside the regenerator, $\mathrm{K}$

$V_{\min , c}$

minimum volume in the compression space, $\mathrm{m}^{3}$ 
$V_{\min , e} \quad$ minimum volume in the expansion space, $\mathrm{m}^{3}$

$V_{\text {swept }, c} \quad$ swept volume in the compression space, $\mathrm{m}^{3}$

$V_{\text {swept,e }} \quad$ swept volume in the expansion space, $\mathrm{m}^{3}$

Greek letters

$\beta \quad$ phase shift between piston and displacer of the SE

$\gamma \quad$ specific heat ratio of the working fluid of the SE

$\varepsilon_{1} \quad$ effectiveness of the regenerator on the heater side

$\varepsilon_{2} \quad$ effectiveness of the regenerator on the cooler side

$\Phi \quad$ Pareto frontier

$\eta_{S E} \quad$ SE efficiency

$\eta \quad$ global mechanical efficiency

$\rho_{g} \quad$ gas phase density, $\mathrm{kg} / \mathrm{m}^{3}$

$\rho_{s} \quad$ solid phase density, $\mathrm{kg} / \mathrm{m}^{3}$

Acronyms

CV Control Volume

FB Fluidized Bed

FBC Fluidized Bed Combustor

LHV Lower Heating Value

LB Lower Bound

MOP Multi Objective Problem

MOGA Multi Objective Genetic Algorithm

SE Stirling Engine

UB Upper Bound

\section{References:}

Angrisani G., Bizon K., Chirone R., Continillo G., Fusco G., Lombardi S., Marra F. S., Miccio F., Roselli C., Sasso M., Solimene R., Tariello F., Urciuolo M. (2012). Development of a New Concept Hybrid Solar-Biomass Cogeneration System, International Conference Contemporary Problem of Thermal Engineering CPOTE 2012, Gliwice, Poland.

Angrisani G., Bizon K., Chirone R., Continillo G., Fusco G., Lombardi S., Marra F. S., Miccio F., Roselli C., Sasso M., Solimene R., Tariello F., Urciuolo M. (2013). Development of a New Concept Hybrid Solar-Biomass Cogeneration System, Energy Conversion and Management, 75, 552-560.

Banduric, R.D., Chen, N. C. J. (1984). Nonlinear analysis of Stirling engine thermodynamics. Technical Report n. ORNL/CON-154, Oak Ridge National Laboratory.

Chen, J. C. (2003). Heat transfer, in Handbook of Fluidization and Fluid-Particle Systems, Chap. 10, Ed. by Yang, W.C. New York, NY: Marcel Dekker, Inc.

Chen, N. C. J., Griffin, E. P. (1983). Effects of pressuredrop correlations on Stirling engine predicted performance. Technical Report n. CONF-830812-52, Oak Ridge National Laboratory.

Di Barba, P. (2010). Multiobjective shape design in electricity and magnetism, 1st Edition., Springer Dordrecht Heidelberg London New York.
Dong, L., Liu, H., Riffat, S. (2009) Development of smallscale and micro-scale biomass-fuelled CHP systems - A literature review. Applied Thermal Engineering, 29, 2119-2126.

Eslick J.C., Miller D.C (2012). A multi-objective analysis for the retrofit of a pulverized coal power plant with a $\mathrm{CO}_{2}$ capture and compression process. Powder Tech. 217, 84-99.

Incropera, F. P., DeWitt, D. P. (1996). Fundamentals of heat and mass transfer. Fourth Edition, Wiley, New York.

Kim, S. Y., J. Huth, J. G. Wood. (2005). Performance Characterization of Sunpower Free-Piston Stirling Engines. Proceedings of AIAA IECEC2005 conference.

Leckner, B. (1998). Fluidized bed combustion: Mixing and pollutant limitation, Progress in Energy and Combustion Science, 24, 31-61.

Logist F., Van Erdeghem P.M.M., Van Impe, J.F., (2009). Efficient deterministic multiple objective optimal control of (bio)chemical processes, Chem. Eng. Science, 64, 2527-2538.

Miccio, F. (2013). On the integration between fluidized bed and stirling engine for micro-generation, Applied Thermal Engineering, 52, 46-53.

Normani, F. (2009). Stirling engine manual. From http://newenergydirection.com/blog/2009/03/stirlingengine-design-program.

Pareto, V. (1896). Cours d'economie Politique. Rouge, Lausanne, Switzerland.

Theis, M., Skrifvars, B.-J., Hupa, M., Tran, H. (2006a). Fouling tendency of ash resulting from burning mixtures of biofuels. Part 1: Deposition rates. Fuel, 85, 1125-1130.

Theis, M., Skrifvars, B.-J., Zevenhoven, M., Hupa, M., Tran, H. (2006b) Fouling tendency of ash resulting from burning mixtures of biofuels. Part 3. Influence of probe surface temperature. Fuel, 85, 2002-2011.

Vos, J. (2006).. Biomass energy for heating and hot water supply in Belarus. Contract Report (BYE/03/G31), BTG.

Walker, G. (1980). Stirling Engines. Oxford: Clarendon Press.

Wiinikka, H., Gebart, R., Boman, C., Boström, D., Nordin, A., Öhman, M. (2006). High-temperature aerosol formation in wood pellets flames: Spatially resolved measurements. Combust. Flame, 147, 278-285. 